Fidya Zahra Afifah, Yanti Setianti, Heru Ryanto Budiana

\title{
TAHAPAN PEMBENTUKAN BRAND AWARENESS NFRT LABEL (NEFERTITI) SEBAGAI EFFORTLESS FASHION MELALUI MEDIA SOSIAL INSTAGRAM
}

\author{
Fidya Zahra Afifah, Yanti Setianti, Heru Ryanto Budiana
}

\author{
Program Studi Hubungan Masyarakat Fakultas Ilmu Komunikasi \\ Universitas Padjadjaran \\ fidyzahra@gmail.com
}

\begin{abstract}
The vastly dynamic movement of fashion industry where many brands are converting to digital marketing, is seen as an opportunity for Indonesian local brands such as NFRT Label (Nefertiti) to build brand awareness. NFRT Label is a woman clothing line that was found in 2011. With their identity as "effortless fashion", NFRT is trying to construct's public awareness towards their brand as a clothing line with sense of effortless style through Instagram. The purpose of this research is to describe how NFRT Label builds its brand awareness as effortless fashion through Instagram. The researcher elaborates the purpose of this reserach in three aspects: how NFRT Label attracts attention on Instagram, creates consumer's comprehension and consumer's retention. The researcher used descriptive method with qualitative data. The result of this research is elaborated based on this research's objectives. In gaining attention, NFRT creates different kinds of contents, collaborates with celebrity endorsers, holding a contest, using hashtag, creative caption-writing, et ce tera. Seeing how NFRT creates comprehension, NFRT gives basic information about their products, collection description, content consistency, creates easy-to-comprehend captions, et ce tera. To create consumer's retention, NFRT shows their signature products, does repetivite contents, manages the time and amount of postings, and use an easy-to-reccall logo. NFRT has done a good job in creating customer's attention through social media although NFRT hasn't given an optimal performance when creating customer's comprehension and retention.
\end{abstract}

Keywords: Brand Awarness, Efforless Fashion, Social Media

\begin{abstract}
Abstrak
Perubahan industri fesyen yang begitu dinamis di mana banyak kegiatan pemasaran yang dilakukan secara digital, menjadikan peluang fesyen lokal Indonesia untuk mengembangkan bisnisnya. NFRT Label adalah sebuah merk fesyen wanita yang berbasis di Jakarta berdiri tahun 2011. NFRT sedang dalam tahapan pembentukan kesadaran merknya melalui media sosial. Dengan identitasnya sebagai "effortless fashion", NFRT berupaya menciptakan kesadaran publik terhadap brand dengan gaya effortless ini. Tujuan penelitian menggambarkan pembentukan brand awareness NFRT Label sebagai effortless fashion melalui media sosial Instagram, melalui gambaran upaya NFRT dalam menarik perhatian konsumen (attention), menciptakan pemahaman (comprehension), dan menciptakan ingatan (retention). Metode penelitian deskriptif kualitatif dengan hasil penelitian menunjukan bahwa dari segi attention, NFRT menciptakan konten yang variatif, penggunaan celebrity endorsement, pelaksanaan kontes, penggunaan hashtag, dan lain-lain. Dilihat dari sisi comprehension, upaya NFRT dalam menciptakan pemahamannya adalah melalui pemberian informasi produk, konsistensi konten, pendeskripsian koleksi, serta menulis caption yang
\end{abstract}


mudah dipahami konsumen. Sementara itu, dari segi retention, upaya NFRT adalah dengan menunjukan produk signature-nya, repetisi konten, penentuan jumlah dan waktu posting, pembagian voucher VIP, penggunaan logo yang mudah diingat, serta konsistensi pada konten yang dipublikasikan itu sendiri. NFRT sudah melakukan tahapan attention dengan cukup baik. Dilihat dari tahapan comprehension, NFRT kurang memaparkan informasi terkait "effortless fashion" kepada followers-nya. Selain itu, pada tahapan retention, NFRT masih kurang optimal dalam menciptakan ingatan tentang karakteristik produknya melalui media sosial Instagram.

Kata kunci : Brand Awarness, Efforless Fashion, Media Sosial

\section{PENDAHULUAN}

NFRT yang dahulu dikenal dengan nama Nefertiti adalah sebuah merk fesyen wanita yang berbasis di Jakarta. NFRT pertama kali didirikan tahun 2011 oleh Prita Widyaputri dengan menjual koleksi aksesoris wanita. Pada tahun 2014, NFRT memulai debut-nya melalui Jakarta Fashion Week 2014 setelah memenangkan Grazia Awards. Kini NFRT tersebar di 18 toko di kota-kota besar di Indonesia seperti Jakarta, Bandung, Bali, Surabaya, Makassar, dan Jogjakarta. Menghadapi kemunduran industri retail fesyen saat ini, Prita Widyaputri selaku pendiri NFRT Label mengatakan,

"Jadi, menurutku sih bukan hanya di dunia bisnis kreatif, tapi memang retail saat ini memang memiliki tantangan: kayak misalnya department stores kayak Debenhams, Matahari, juga menghadapi tantangan, karena banyak yang tutup. Tetapi, tantangan ini dijadikan peluang oleh brand-brand lokal, seperti NFRT. Sekarang kan dunia sudah borderless, jadi banyak konsumen yang pengen belanja tapi gak mau ke mall. Di satu sisi memang menjadi peluang bagi brand-brand lokal yang menawarkan sisi unique selling point yang berbeda."

NFRT melihat fenomena tersebut sebagai peluang. Hal ini juga didukung oleh data yang didapatkan dari We Are Social di bulan Januari 2018 di mana terdapat 132.7 juta pengguna internet di Indonesia. Sementara itu, penetrasi penggunaan internet Indonesia mencapai 50\%, hal ini mengartikan bahwa penduduk hampir 50\% penduduk dari berbagai usia menggunakan internet. Dengan peluang pembeli yakni pengguna internet yang mencapai 50\% dari jumlah penduduk total Indonesia yaitu 265.4 juta jiwa, NFRT turut terjun dalam memanfaatkan peluang ini. Selain itu, menurut data yang didapatkan oleh We Social pada bulan Januari 2018, dari 132.7 juta pengguna internet, sebanyak 130 juta di antaranya adalah pengguna aktif dari media sosial. Dari data tersebut, sebanyak $38 \%$ dari pengguna media sosial adalah pengguna Instagram. Melihat peluang ini, NFRT mulai membuat akun Instagram-nya di tahun 2013.

"Awalnya NFRT masuk ke dunia digital sih sebenernya kayak proses waktu aja sih sebenernya. awal-awal masuk 2011 itu kita main Facebook, bikin fan page, terus kayak Twitter, kalau Path kayaknya engga deh. Terus 2012 itu masih disitu-situ juga, cuma 2013 kita mulai masuk ke dunia Instagram, gitu sih. Aku ngeliatnya pengguna Facebook tetep banyak tapi audiens kita udah mulai bergeser pada pakai Instagram."

Tujuan NFRT untuk menggunakan Instagram adalah untuk menjangkau target pasar NFRT tersebut. Menurut wawancara yang dilakukan bersama Prita Widyaputri, target pasar NFRT adalah wanita dari range umur 18 hingga 35 tahun, yang menyukai fesyen yang mudah dipadupadankan dan tidak membutuhkan usaha yang banyak untuk tampil stylish. Secara geografis, NFRT menargetkan kota-kota besar di 
Indonesia seperti Jakarta, Bandung, Surabaya, Medan, dan kota-kota besar lainnya.

Instagram NFRT memiliki
sebanyak 15.629 follower, di mana
Berdasarkan wawancara pra riset yang
dilakukan dengan Prita Widyaputri, owner
NFRT Label, NFRT memang belum
termasuk dalam kategori brand besar di
industri fesyen lokal, akan tetapi NFRT
sedang berusaha untuk mencapai tahap
tersebut. Menurut data yang didapatkan
dari business insight NFRT Label, follower
NFRT didominasi oleh wanita, dengan
kisaran umur 25-34 tahun. Selain itu,
pengikut NFRT didominasi oleh penduduk
kota-kota besar seperti Jakarta, Bandung,
Surabaya, Tangerang, dan Bekasi.

Prita Widyaputri sebagai owner dari NFRT menjelaskan bahwa citra yang ingin dibangun melalui NFRT adalah Effortless Fashion Style. Menurut artikel yang berjudul "Achieving Effortless Style: Do's and Don'ts" pada yang ditulis oleh JJawa Liu dalam situs "Beige Renegade", Effortless style dapat diartikan sebagai "Effortless style means keeping your style simple, butnever boring. It means appearing as though you randomly threw a few things on, and it just happens to look put-together. It's the illusion that you didn't even try (when of course, you actually did)." (Gaya 'Effortless' berarti mengusahakan agar gaya Anda tetap simpel, tapi tidak membosankan. Gaya ini berarti memadu padankan beberapa hal sehingga ketika dipadukan menjadi 'bagus' dan menciptakan ilusi seolah-olah Anda tidak menggunakan banyak 'usaha' dalam menciptakan gaya Anda.) Gaya "effortless fashion" ini juga dituangkan dalam misi yang ditetapkan oleh NFRT Label sebagai sebuah brand, yakni "Produce sophisticated casual ready-to-wear fashion line with an effortless style for modern women. (Memproduksi pakaian casual dengan kualitas yang baik dan memberi aksen 'effortless' untuk wanita modern)".

Mega Citra selaku Managing Director juga mengatakan bahwa pertumbuhan Instagram NFRT bergerak secara perlahan sehingga NFRT masih dalam proses membangun akun Instagram yang dimilikinya. Sementara itu, Prita Widyaputri menjelaskan bahwa kesadaran atau awareness konsumen terhadap NFRT sebagai brand masih cenderung kurang. Oleh karena itu, NFRT berupaya untuk membentuk brand awareness-nya sebagai effortless fashion. Prita Widyaputri juga mengatakan bahwa pembentukan kesadaran merk atau brand awareness sangatlah penting untuk dapat mendapatkan brand loyalty dari konsumen dan akan berpengaruh kepada penjualan.

Tantangan lain yang dihadapi NFRT dalam kegiatan penjualan onlinenya adalah penurunan jumlah likes. Berdasarkan wawancara pra riset yang dilakukan dengan Prita Widyaputri, NFRT mengalami penurunan jumlah likes, di mana jumlah likes tidak berbanding lurus dengan jumlah followers-nya. Menurut Prita Widyaputri, jumlah likes ini tergolong sangat sedikit dibandingkan brand lain.

"Dari setiap post, kita hanya dapat meraih likes dari 20 hingga 40 likes. Kita punya 15,300 followers, anehnya adalah kita hanya mendapatkan sekitar ya mungkin $0,25 \%$ likes dari jumlah followers tersebut. Menurutku sangat sedikit, ya. Dibandingkan brand lain."

Untuk mencapai tujuan kesadaran merk, terdapat beberapa aspek yang harus diperhatikan. Menurut Ronald D. Smith (2002:75), untuk mencapai kesadaran (Awareness), dibutuhkan beberapa objektif, yakni perhatian (Attention). pemahaman (Comprehension), dan daya ingat (Retention). Menurut Smith, strategi dalam mencapai Awareness tersebut harus 
JURNAL NOMOSLECA

Volume 5 Nomor 1, April 2019

dapat menarik perhatian khalayak, dapat dipahami dan diingat oleh khalayak.

\section{Brand Awareness}

Aaker (1991:61) mendefeinisikan Brand Awareness itu sendiri sebagai kemampuan dari seseorang yang merupakan calon pembeli (potential buyer) untuk mengenali (recognize) atau menyebutkan kembali (recall) suatu merek merupakan bagian dari suatu kategori produk.

Menurut Smith (2002: 75), untuk mewujudkan brand awareness harus melewati beberapa tahapan yakni attention, comprehension, dan retention. Adapun penjelasan dari tahapan-tahapan (a) attention, Sanjaya (2009:115) menambahkan dengan ilustrasi produk yang jelas, baik melalui tulisan, foto maupun video, diharapkan dapat menarik dan memudahkan calon konsumen dalam melihat produk-produk yang ditawarkan. Dan tahapan (b) comperhension, dalam tahapan ini khalayak sudah menginterpretasi informasi menjadi arti yang lebih spesifik. (c) retention, Smith (2002:250) mengungkapkan bahwa keberhasilan dalam menciptakan ingatan konsumen tentang pesan yang ingin disampaikan dalam membentuk awareness adalah menilai kemampuan konsumen tersebut dalam mendeskripsikan kembali pesan yang disampaikan.

\section{Social Media :Instagram}

Social media secara umum menurut Luttrell (2015:55) didefinisikan sebagai adalah aktivitas, praktek, dan kebiasaan diantara beberapa komunitas manusia yaang berkumpul secara online untuk membagikan informasi, pengetahuan, dan opini melalui media conversational. Media conversational adalah sebuah aplikasi berbasis web yang memungkinkan penggunanya untuk membuat, mengirim, dan membagikan sebuah konten dalam bentuk susunan kata - kata, gambar, video, dan atau audio.

Luttrell (2015:191) mendefinisikan Instagram sebagai sebuah aplikasi yang berdiri di bawah kepemilikan Facebook. Instagram merupakan aplikasi yang memungkinkan penggunanya untuk membagikan foto mereka ke satu sama lain secara gratis. Aplikasi ini juga memungkinkan penggunanya untuk mengambil foto, mengaplikasikan filter pada foto mereka, dan membagikan foto tersebut melalui Instagram dan media sosial lainnya, seperti Facebook, Twitter, Foursqure, Tumblr, Flickr, dan Posterous.

Instagram memiliki banyak fitur untuk dapat menarik pengguna. Fitur-fitur ini dapat dimanfaatkan oleh pengguna untuk memudahkan dalam berkomunikasi, memudahkan dalam melakukan posting, hingga memberi aksen estetika terhadap foto yang akan di-posting.

\section{Effortless Fashion}

Jiawa Liu (2015) menulis artikel yang berjudul "Achieving Effortless Style: Do's and Don'ts" dalam situs "Beige Renegade" memberikan definisi dari effortless style. Dalam artikel tersebut, effortless style diartikan sebagai berikut. "Gaya 'Effortless' berarti mengusahakan agar gaya Anda tetap simpel, tapi tidak membosankan. Gaya ini berarti memadu padankan beberapa hal sehingga ketika dipadukan menjadi 'bagus' dan menciptakan ilusi seolah-olah Anda tidak menggunakan banyak 'usaha' dalam menciptakan gaya Anda"

Menurut Natalia Sphek (2016), seorang style consultant mengatakan hal yang paling penting dari gaya effortless adalah detail kecil. Natalia Sphek menjelaskan bahwa seseorang bisa saja memakai pakaian yang paling simpel dan 
tetap terlihat elegan. Akan tetaoi ada detaildetail kecil yang digunakan adalah yang membuat seseorang terlihat berbeda Sebagai contoh, kalung yang dipadupadankan dengan sweater, panjang dan bentuk dari celana panjang, atau penggunakan scarf di atas kemeja atau bagaimana seseorang memadupadankan celana training-nya dengan coat, atau bagaimana seseorang menggulung lengan pakaiannnya. Di sinilah seseorang dapat bermain dan mengekspresikan gaya khas sendiri.

\section{METODE PENELITIAN}

Muhadjir (2000:12) menjelaskan bahwa ada metodologi penelitian kualitatif yang landasan berfikirnya adalah filsafat positivisme. Bila dideskripsikan sederhana, metodologi penelitian yang disebutkan tersebut menggunakan pola fikir kuantitatif (mengejar yang terukur, teramati, yang empiri sensual, menggunakan logika matematik, dan membuat generalisasi atas rerata); mengakomodasi deskripsi verbal yang menggantikan angka, atau menggabungkan olahan statistik dengan olahan verbal dengan pola fikir tetap kuantitatif.

Dari penjelasan di atas, peneliti menggunakan paradigma positivisme dengan metode penelitian deskriptif dan jenis data kualitatif; di mana konsep yang digunakan dirumuskan secara spesifik, dan tidak menggunakan ulasan meluas yang tidak langsung relevan. Selain itu, peneliti juga memisahkan antara subjek dan objek penelitian untuk mendapatkan hasil yang objektif serta peneliti juga mendeskripsikan data yang bersifat verbal dalam penelitian ini.

Penulisan penelitian ini menggunakan metode deskriptif dengan pendekatan kualitatif. Hal ini berkaitan dengan penguraian pengalaman tim NFRT Label dalam menyusun dan mengimplementasikan objektif pembentukan Brand Awareness. Metode deskriptif adalah suatu metode dalam meneliti status sekelompok manusia, suatu objek, suatu set kondisi, suatu sistem, pemikiran ataupun suatu kelas peristiwa pada masa sekarang. Penelitian deskriptitf hanya memaparkan suatu situasi atau peristiwa. Penelitian ini tidak mencari suatu hubungan, tidak menguji hiotesis atau membuat prediksi (Ardianto, 2011:49).

\section{HASIL DAN PEMBAHASAN}

Dalam bab ini, penulis menjelaskan, mendeskripsikan, dan juga membahas hasil dari penelitian yang didapatkan dari berbagai data selama penelitian dilangsung. Penelitian yang berjudul "Pembentukan Brand Awareness NFRT LABEL sebagai Effortless Fashion melalui Media Sosial Instagram", memiliki tujuan untuk mengetahuui bagaimana Brand Awareness NFRT Label dibentuk sebagai effortless fashion melalui Instagram. Pembentukan Brand Awareness itu sendiri terdiri dari beberapa tahapan yakni menarik perhatian konsumen (attention), menciptakan pemahaman (comprehension), dan menciptakan daya ingat (retention).

Pertama, peneliti membahas dari segi menarik perhatian (attention). Hasil wawancara peneliti dengan pihak NFRT Label menyatakan bahwa upaya NFRT dalam menarik perhatian konsumennya adalah sebagai berikut. Yang pertama, NFRT memikirkan penyajian masingmasing konten. Menurut NFRT, konten yang disediakan bukan hanya konten yang menjual produk, tetapi juga konten yang dapat menghibur konsumennya. Dalam hal 
ini yang dimaksud adalah menghibur konsumennya secara visual, dengan konten yang memiliki estetika yang "enak" dipandang mata. Konten yang ditawarkan NFRT antara lain foto produk, foto inspirasi gaya hidup seputar travel, konten musik berupa playlist, konten foto saat prouk dipakai oleh konsumennya, dan konten seputar informasi terkait NFRT itu sendiri. Selain dari visual konten itu sendiri, yang harus diperhatikan adalah caption. Menurut Kasali (1995) ada beberapa dalam penulisan caption yang harus diperhatikan. Yang pertama adalah penggunaan headline yang mengarahkan pada maksud dari konten tersebut. NFRT menggunakan headline yang memberi tahu maksud dari setiap konten agar konsumen lebih tertarik untuk melihat konten yang ditawarkan. Pernyataan ini didukung oleh pendapat Achmad Hafizh. Menurutnya, caption yang baik adalah caption yang menyertakan isi pokok dari konten tersebut pada tiga baris pertama.

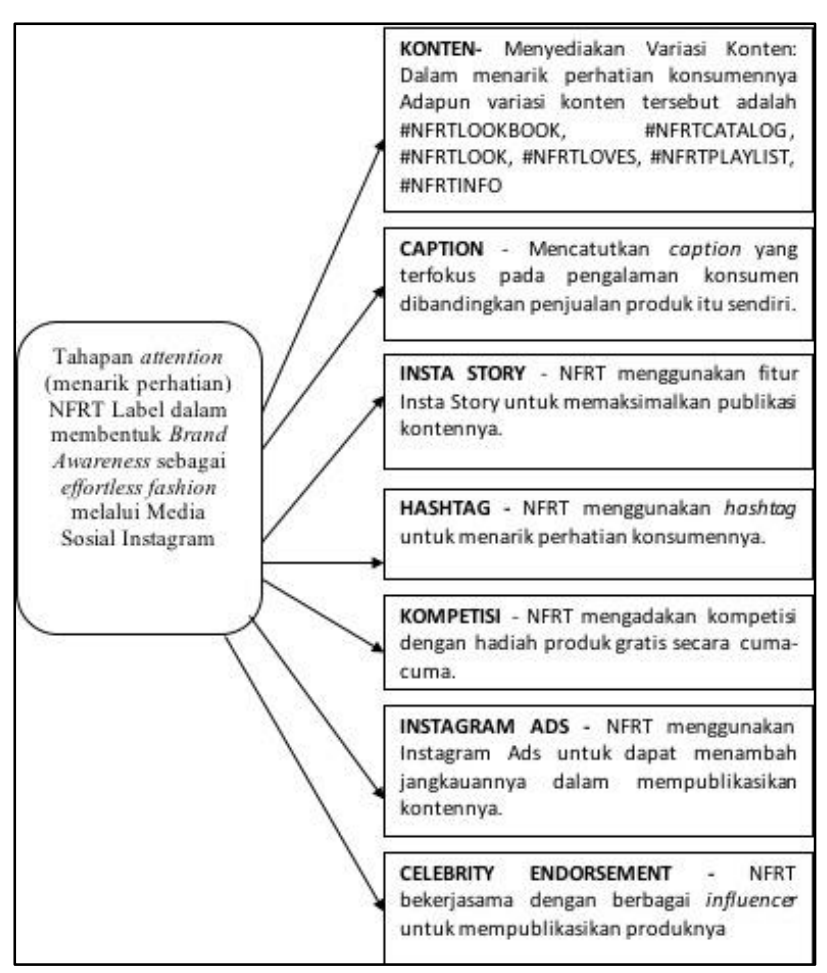

Gambar 1.1 Tahapan Attention NFRT dalam membentuk Brand Awareness sebagai Effortless Fashion Melalui Media Sosial Instagram
Selain dari penulisan caption, penggunaan fitur Instagram juga memiliki pengaruh dalam menarik perhatian konsumen. Berdasarkan hasil wawancara yang dilakukan dengan tim NFRT Label, NFRT menggunakan beberapa fitur di Instagram untuk berupaya menarik perhatian konsumennya. Salah satu fitur tersebut adalah hashtag. NFRT menggunakan dua jenis hashtag: yang pertama adalah hashtag yang digunakan sebagai pengklasifikasi jenis konten yang ditawarkan. Hashtag tersebut adalah \#NFRTLOOKBOO, \#NFRTCATALOG, \#NFRTLOVES, \#NFRTLOOK, \#NFRTPLAYLIST, dan \#NFRTINFO. Menurut Agung (2012:105), penggunaan hashtag membantu orang lain menemukan foto-foto yang satu tema. Sebagai contoh, foto-foto Starbucks sangat mudah ditemukan kalau kita menulis hashtag \#coffee. Pertimbangkan untuk menggunakan hashtag agar ketika orangorang mencari kata kunci tertentu, foto yang dipublikasikan ikut ditemukan.

Selain fitur hashtag, fitur lain yang digunakan NFRT adalah fitur Insta Story. Berdasarkan wawancara yang dilaksanakan dengan pihak NFRT, fitur Insta Story sekarang cenderung lebih diminati oleh para pelanggan. Menurut wawancara yang dilakukan dengan Achmad Hafizh sebagai digital consultant, memang terjadi perubahan perilaku dalam Instagram. Menurut beliau, pengguna Instagram lebih sering memposting kegiatan sehari-harinya dengan konten dengan estetika yang tidak sebagus dnegan konten yang diposting melalaui profil Instagram mereka. Hal ini lah yang menyebabkan pengguna Instagram lebih sering menggunakan Insta Story dibandingkan melihat foto di dalam profil Instagram pengguna lainnya.

Fitur lainnya yang mempermudah NFRT dalam upaya mendaptkan perhatian 
konsumen adalah fitur Instagram Ads. Instagram Ads merupakan fitur iklan berbayar yang ditawrkan Instagram. Fitur ini memudahkan pengiklan untuk dapat ditemukan oleh target penjualnya. Menurut Achmad Hafizh, fitur ini lebih efektif dibandingkan penggunaan endorsement. Hal ini dikarenakan fitur ini dapat mentarget audiens tertentu yang sesuai degan target pasar brand tersebut. Dalam penggunaan fitur ini, NFRT menggunakan foto produknya atau foto yang dikenakan celebrity endorsement dalam menarik perhatian konsumennya.

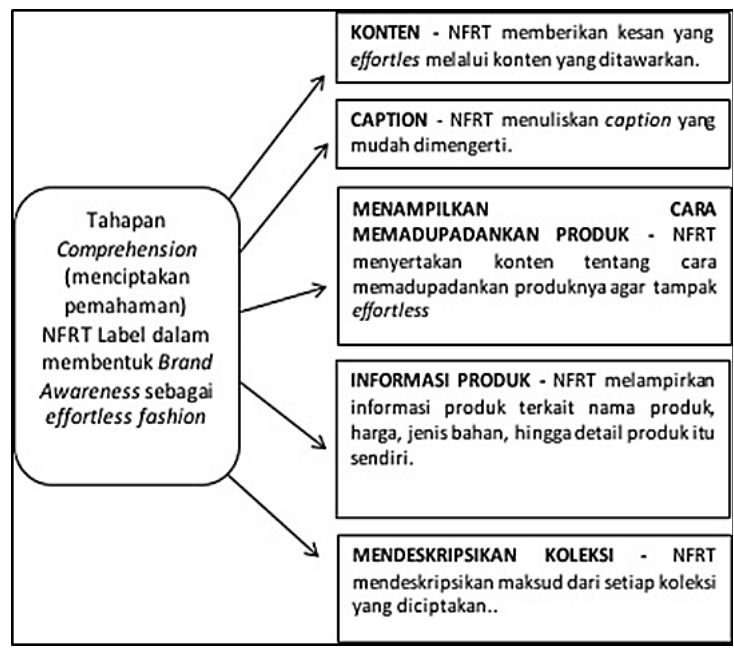

Gambar 1.2 Tahapan

Comprehension NFRT dalam membentuk

Brand Awareness sebagai Effortless

Fashion Melalui Media Sosial Instagram

Kedua, peneliti membahas dari segi menciptakan pemahaman (comprehension). Hasil wawancara yang dilakukan oleh tim NFRT itu sendiri, cara NFRT menciptakan pemahaman mengenai effortless fashion itu sendiri melalui konten grafis yang mereka tawarkan. Dengan memproduksi variasi konten yang memprioritaskan konsistensi secara estetika di berbagai komponen konten tersebut: mulai dari warna, peletakan wording, hingga penggunaan caption itu sendiri menjadi upaya utama NFRT dalam menciptakan pemahaman mengenai produk-nya. Dalam menulis caption, NFRT cenderung menonjolkan pengalaman yang ingin ia ciptakan saat konsumen mengenakan pakaian NFRT. Pesan mengenai "effortless fashion" itu sendiri tercermin dari penggunaan kata-kata seperti "effortless" atau "versatile" yang menjadi pendukung pembentukan brand effortless fashion ini. Pihak NFRT merasa penyampaian pesan secara tersirat dapat membentuk pemahaman konsumen secara sendirinya.

Berdasarkan proses pemahaman produk yang dicetuskan oleh Graeff (1996), dalam menciptakan pemahaman produk yang harus diperhatikan adalah informasi dari produk itu sendiri. Dalam hal ini, NFRT menampilkan beberapa hal yang menjadi informasi dasar suatu produk. Hal tersebut adalah pencantuman harga, pencantuman nama produk, pencantuman informasi di mana produk-produk tersebut dapat diperoleh, hingga detail yang ditonjolkan dari setiap produk. Informasiinformasi tersebutlah yang akan menjadi pengetahuan konsumen mengenai produk NFRT. Dari informasi tersebut, konsumen dapat menggambarkan produk NFRT berdasarkan informasi dasar mengenai produk tersebut. "NFRT menjual celana berwarna krem dengan detail kerut yang harganya adalah 390.000". Pengetahuan dasar ini harus disertai dengan informasi tentang brand yang ingin dibentuk sehigga konsumen dapat membentuk opini tentang brand berdasarkan informasi yang disediakan, misalnya "Celana NFRT itu mudah dipadupadankan dengan beberapa atasan yang berbeda dan tetap terlihat stylish tanpa harus ditambahkan aksesoris lain." Tantangan NFRT tentu terletak pada bagaimana konsumen dapat memberikan opininya bahwa kesan yang diciptakan NFRT adalah "effortless fashion".

NFRT itu sendiri telah memposting beberapa konten yang menunjukan cara memadupadankan pakaian NFRT. Konten 
JURNAL NOMOSLECA

Volume 5 Nomor 1, April 2019

tersebut berbentuk konten grafis dan juga penggunaan caption yang dicatutkan NFRT di mana caption tersebut menyertakan instruksi atau cara memadupadankan pakaian NFRT. Kalimat seperti "Pair it with your---" menunjukan bagaimana cara memadupadankan produk NFRT. Hal lain yang merupakan usaha NFRT dalam menciptakan pemahaman konsumennya adalah dengan menjelaskan maksud dari setiap koleksi yang dirilis. Terdapat penjelasan singkat mengenai makna dibalik koleksi tersebut. Sebagai contoh, koleksi The Nomads adalah koleksi yang terinspirasi dari gaya hidup masyarakat nomaden. Secara keseluruhan, NFRT tidak pernah secara tersurat menyampaikan bahwa brand-nya adalah effortless fashion. Melalui konten yang didesain dan caption yang menjelaskan konten tersebut, NFRT berharap dapat menciptakan pemahaman konsumen mengenai brand yang ingin dibentuknya.

Ketiga, peneliti membahas dari segi menciptakan ingatan (retention). Salah satu upaya NFRT dalam menciptaakndaya ingat konsumen terhadap brand-nya adalah dengan memerhatikan jumlah konten yang diposting setiap harinya. Jumlah konten yang diposting tidak menentu karena NFRT selalu menyesuaikan dengan traffic atau keramaian dari aktivitas akun Instagramnya tersebut. Berdasarkan wawancara yang dilakukan dengan Mega Citra, Managing Director NFRT Label, jumlah konten yang diposting saat traffic sedang tinggi adalah empat hingga 6 konten dalam feeds. Sementara itu, ketika traffic sedang rendah, NFRT hanya memposting sebanyak 1 post atau tidak memposting konten sama sekali. Berbeda dengan Insta Story, setiap harinya NFRT mem-posting sebanyak 4 konten setiap harinya. Hal ini disesuaikan dengan perubahan perilaku konsumen yang lebih sering melihat Insta Story dibandingkan konten yang diposting ke dalam akun profil Instagram.

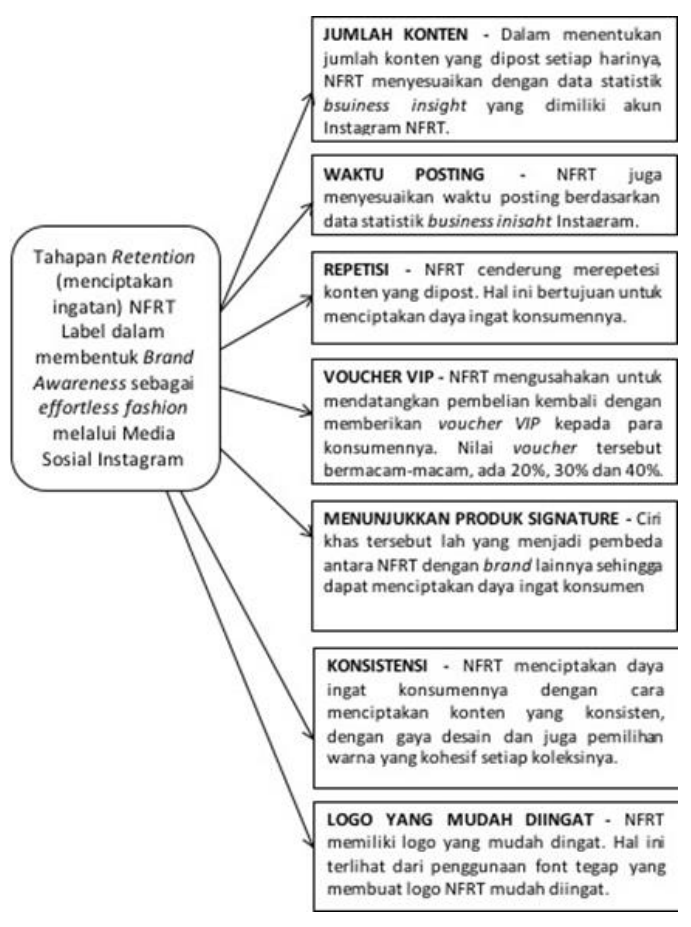

\section{Gambar 1.3 Tahapan Retention NFRT dalam membentuk Brand Awareness sebagai Effortless Fashion Melalui Media Sosial Instagram}

Selain memerhatikan jumlah konten yang diposting, NFRT juga memerhatikan waktu yang tepat untuk memposting. Pemilihan waktu ini didasari oleh business insight yang ada di dalam Instagram NFRT: saat traffic tinggi, NFRT memposting pada waktu yang ditentukan melalui statistik tersebut. Mega Citra menjelaskan bahwa secara keseluruhan, NFRT kerap memposting pada pagi hari sebelum orang-orang menjalankan aktivitasnya, siang hari saat orang-orang sedang beristirahat, dan malam hari saat orag-orang terjebak kemacetan seusai pulang kantor. Pemilihan waktu untuk mem-posting konten ini tentu berbeda-beda tergantung pada statistik business insight Instagram NFRT.

Usaha lain yang dilakukan NFRT adalah menunjukan produk-produk ciri khas NFRT. Berdasarkan hasil wawancara yang dilakukan bersama Luqyana Yahya, NFRT kerap menonjolkan ciri khas dari 
setiap koleksinya. Melalui koleksi The Nomads, NFRT menunjukkan perpaduan linen dan lurik dalam koleksinya. Melalui koleksi Wake Up + Repeat Vol.1, NFRT menunjukan perpaduan motif marmer dalam koleksinya. Melalui akun Instagramnya, NFRT juga menunjukan deretan best style yang mereka miliki secara repetitif agar ketika follower NFRT melihat konten tersebut, mereka bisa mengidentifikasi bahwa baju tersebut adalah produk NFRT. Berdasarkan kalender promo yang disusun oleh tim NFRT, setiap bulannya terdapat produk yang di highlights dalam kurun waktu tersebut. Dengan repetisi produk tersebut, diharapkan NFRT dapat menciptakan daya ingat konsumen.

Repetisi atau pengulangan pesan suatu iklan dapat menyebabkan perubahan dalam pengetahuan, sikap, dan perilaku konsumen (Kardes, 2001). Suatu pesan sama yang senantiasa diulang-ulang pada akhirnya akan berakibat diingatnya pesan tersebut. Para peneliti berpendapat bahwa pengulangan itu ada batasnya, dimana jumlah optimumnya adalah tiga kali, lebih dari tiga kali akan membuatnya mubazir. Ini yang disebut three-hit theory (Schiffman dan Kanuk, 2000) untuk membuat konsumen sadar terhadap produk. Akan tetapi jelas bahwa terlalu banyak pengulangan dapat menimbulkan efek yang merugikan, yaitu sesudah melalui tertentu pengulangan, maka pengulangan tambahan mungkin mengurangi daya tarik konsumen terhadap produk yang dipublikasikan.

Usaha lain yang dilakukan NFRT adalah penggunaan logo yang mudah diingat. Berdasarkan wawancara yang dilakukan dengan tim NFRT, NFRT memiliki logo yang menggunakan huruf tegak yakni "Orator". Logo NFRT itu sendiri tidak berbentuk simbol tetapi nama brand NFRT itu sendiri. Alhasil, ketika melihat logo NFRT, orang lain langsung mengenali bahwa itu adalah logo dari NFRT. Upaya terakhir yang NFRT lakukan adalah menjalin hubungan baik dengan konsumennya. Berdasarkan wawancara yang dilakukan dengan tim NFRT, NFRT kerap memberikan potongan harga dalam bentuk voucher pada pelanggan yang melalukan pembelian. Voucher ini berlaku untuk pembelian berikutnya. Hal ini dilakukan NFRT untuk menimbulkan pembelian kembali.

Aaker (1991) mengatakan bahwa, "brand is signal". Artinya sebuah merk memberi tanda pada konsumen tentang asal produk dan melindungi konsumen dan produsen dari pesaing yang berusaha meniru. Jadi merk merupakan alat pembeda antara satu produk dengan produk lainnya. Dalam hal ini, NFRT belum dapat menunjukkan ciri khas yang ia miliki sebagai pembeda dengan brand lainnya. Peneliti merasa harus ada suatu hal yang membuat NFRT unik yang kemudian dapat membantu konsumen dalam menciptakan daya ingat tentang NFRT itu sendiri.

\section{PENUTUP}

\section{Simpulan}

Dilihat dari aspek menarik perhatian, NFRT telah menciptakan variasi konten, penyusunan caption yang menonjolkan pengalaman konsumen dibandingkan upaya penjualan produk, penggunaan hashtag, kerjasama melalui endorsement, serta mengadakan kompetisi. Tetapi NFRT belum menggunakan slogan sebagaimana yang disarankan oleh Kasali (1995). Secara kesluruhan dalam aspek attention, upaya NFRT sudah cukup baik. Dilihat dari segi menciptakan pemahaman, NFRT mencantumkan informasi dasar seputar produk seperti nama produk, harga produk, dan bahan yang digunakan melalui caption Instagram. 
Tahapan kedua dalam membentuk brand awareness adalah menciptakan pemahaman. Dalam menciptakan pemahaman sebagai effortless fashion, NFRT juga menciptakan konsistensi konten yang menggunakan materi grafis yang sederhana sehingga diharapkan dapat menimbulkan kesan effortless melalui konten yang ditawarkan. Selain itu, NFRT juga mencantumkan maksud dari setiap koleksi dan bagaimana madupadankan koleksinya melalui caption dan materi grafis. Dilihat dari aspek pemahaman, perlu adanya konten yang lebih merujuk pada pesan "effortless fashion" itu sendiri. Secara visual, NFRT memang bermaksud menyampaikan pesan tersebut. Tetapi, NFRT tidak menyampaikan pesan tersebut secara spesifik. Berdasarkan proses pemahaman oleh Graeff dan Olson (1995), untuk seorang konsumen menciptakan makna mengenai suatu produk harus disertai pengetahuan mengenai lingkungan sekitarnya sehingga konsumen tersebut memberi makna terhadap suatu produk berdasarkan lingkungan sekitarnya. Dalam hal ini, NFRT kurang menyampaikan informasi mengenai bagaimana "effortless fashion" itu sendiri dalam lingkungan sekitar konsumen.

Tahapan ketiga untuk membentuk brand awareness adalah menciptakan daya ingat (retention). Dilihat dari segi daya ingat, NFRT telah melakuka repetisi atau pengulangan pada konten yang ditawarkan. NFRT juga telah menonjolkan produkproduk andalannya secara repetitif agar membuat konsumen mereka mengingat bahwa produk tersebut adalah produk NFRT. NFRT juga berpendapat bahwa untuk menciptakan konten yang mudah diingat adalah dari konsistensi konten itu sendiri. Upaya lainnya yang NFRT lakukan adalah menjalin hubungan baik dengan konsumennya dengan cara pemberian voucher diskon untuk pembelian selanjutnya. Secara keseluruhan, upaya
NFRT dalam menciptakan daya ingat sudah masih kurang optimal. Hal ini dikarenakan NFRT belum terfokus pada perbedaan mendasar yang mereka miliki sebagai suatu brand yang membedakan NFRT dengan brand lainnya.

\section{Saran}

Peneliti berpendapat bahwa upaya pembentukan brand awareness NFRT label sebagai effortless fashion belum cukup optimal. Oleh karena itu, peneliti ingin menyampaikan beberapa saran yang diperoleh dari hasil dan pembahasan penelitian. Dalam menarik perhatian konsumen, usaha NFRT sudah cukup baik. Perbedaan media sosial dengan media elektronik adalah adanya interaksi langsung antara penjual dan pembeli. Melalui media sosial, pembeli bisa saja memberikan komentar terhadap produk NFRT yang dapat direspon oleh penjualan. Perbedaan ini lah yang menurut peneliti dijadikan kesempatan untuk NFRT dalam menjalin hubungan baik dengan konsumennya. Usaha ini dapat dilakukan dengan cara yang berbeda dalam menjawab komentar konsumen. Dengan komunikasi yang dilakukan dengan konsumen yang bersifat lebih personal, konsumen akan memiliki kedekatan diri dengan NFRT.

Dari segi menciptakan pemahaman, yang dilakukan NFRT sudah cukup baik. Akan tetapi, akan lebih baik apabila NFRT menciptakan konten yang secara spesifik bermaksud untuk menyampaikan pesan seputar "effortless fashion" itu sendiri bukan hanya menyelipkan maksud tersirat dalam konten-konten tersebut. Usaha yang dapat dilakukan NFRT adalah membuat video singkat tentang seorang wanita sibuk yang dengan mudah dapat tampil stylish setelah memadupadankan pakaian NFRT.

Sementara itu, dilihat dari segi menciptakan daya ingat, upaya yang 
dilakukan NFRT sudah cukup baik. Akan tetapi, NFRT harus dapat menonjolkan keunikan NFRT sebagai brand dan mengkomunikasikannya dalam bentuk konten di Instagram. Sebagai contoh, brand A menunjukan keunikannya sebagai ecofriendly fashion, brand tersebut menciptakan konten video yang menceritakan bagaimana brand tersebut membuat pakaian dari bahan daur ulang. Dengan menonjolkan keunikan sebagai brand, NFRT akan lebih mudah dalam menciptakan daya ingat konsumennnya.

\section{DAFTAR PUSTAKA}

Aaker, David A. 1991. Managing Brand Equity: Capitalizing on the Value of a Brand Name. New York: The Free Press

Ardianto, Elvinaro .2011. Metodologi Penelitian untuk Public Relations Kuantitatif dan Kualitatif. Bandung: Remaja Rosdakarya.

.Kardes, Frank, R. 2001. Consumer Behnviour. New York: Mac Millan PublishingCompany.

Kasali, Rhenald. 1995. Manajemen Periklanan - Konsep dan Aplikasinya di Indonesia. Jakarta : Pustaka Utama Grafiti.

Luttrell, Regina. 2015. Social Media: How To Engage, Share, and Connect. London: Rowman \& Littlefield.

Muhadjir, Noeng. 2002. Metodologi Penelitian Kualitatif Edisi IV. Yogyakarta:Penerbit Rake Sarasin
Sanjaya, Ridwan. 2009. Creative Digital Marketing. Jakarta: PT Elex Media Komputindo.

Schiffman, Leon G. \& Leslie L. Kanuk. 2000. Consumer Behavior. Fifth Edition. Prentice-Hall Inc. New Jersey.

Smith, D Ronald. 2002. Strategic Planning for Public Relations, second edition, Laurence Erlbaum Associates Publisher, London.

Timothy R. Graeff and Jerry C. Olson (1994) ,"Consumer Inference As Part of Product Comprehension", in NA - Advances in Consumer Research Volume 21, eds. Chris T. Allen and Deborah Roedder John, Provo, UT : Association for Consumer Research, Pages: 201207.

\section{Sumber lain :}

Liu, Jiawa. 2015. Achieving Effortless Style: Do's and Don'ts. googleusercontent.com/search?q= 1p2ko4n5RqAJ:www.beigerenega de.com/2015/04/09/achievingeffortless-style-important-dos-anddonts/+\&cd=1\&hl=id\&ct

$=\mathrm{clnk} \& \mathrm{gl}=\mathrm{id}$

Sphek, Natalia. 2016. Myth of Effortless Style by Natalia Sphek http://nataliashpek.com/mytheffortless-style/ 